\title{
Transcriptome Analysis of Potato Infected with the Necrotrophic Pathogen Alternaria solani
}

\author{
Sophie M. Brouwer ${ }^{1, *}$, Maja Brus-Szkalej ${ }^{1} \mathbb{D}$, Ganapathi V. Saripella ${ }^{2} \mathbb{D}$, Dong Liang ${ }^{1,3}$, Erland Liljeroth ${ }^{1} \mathbb{D}$ \\ and Laura J. Grenville-Briggs 1,*
}

1 Department of Plant Protection Biology, Swedish University of Agricultural Sciences, P.O. Box 7070, SE-750 07 Uppsala, Sweden; maja.brus@slu.se (M.B.-S.); Dong.Liang@slu.se (D.L.); Erland.Liljeroth@slu.se (E.L.)

2 Department of Plant Breeding, Swedish University of Agricultural Sciences, P.O. Box 7070, SE-750 07 Uppsala, Sweden; ganapathi.varma.saripella@slu.se

3 Institute of Plant Protection, Jiangsu Academy of Agricultural Sciences, Nanjing 210014, China

* Correspondence: sophie.brouwer@slu.se (S.M.B.); laura.grenville.briggs@slu.se (L.J.G.-B.)

check for updates

Citation: Brouwer, S.M.; Brus-Szkalej, M.; Saripella, G.V.; Liang, D.; Liljeroth, E.;

Grenville-Briggs, L.J. Transcriptome Analysis of Potato Infected with the Necrotrophic Pathogen Alternaria solani. Plants 2021, 10, 2212. https:// doi.org/10.3390/plants10102212

Academic Editors: Rafał Ogórek and Agata Piecuch

Received: 16 August 2021

Accepted: 14 October 2021

Published: 18 October 2021

Publisher's Note: MDPI stays neutral with regard to jurisdictional claims in published maps and institutional affiliations.

Copyright: (c) 2021 by the authors. Licensee MDPI, Basel, Switzerland. This article is an open access article distributed under the terms and conditions of the Creative Commons Attribution (CC BY) license (https:// creativecommons.org/licenses/by/ $4.0 /)$.
Abstract: Potato early blight is caused by the necrotrophic fungus Alternaria solani and can result in yield losses of up to $50 \%$ if left uncontrolled. At present, the disease is controlled by chemical fungicides, yet rapid development of fungicide resistance renders current control strategies unsustainable. On top of that, a lack of understanding of potato defences and the quantitative nature of resistance mechanisms against early blight hinders the development of more sustainable control methods. Necrotrophic pathogens, compared to biotrophs, pose an extra challenge to the plant, since common defence strategies to biotic stresses such as the hypersensitive response and programmed cell death are often beneficial for necrotrophs. With the aim of unravelling plant responses to both the early infection stages (i.e., before necrosis), such as appressorium formation and penetration, as well as to later responses to the onset of necrosis, we present here a transcriptome analysis of potato interactions with $A$. solani from $1 \mathrm{~h}$ after inoculation when the conidia have just commenced germination, to $48 \mathrm{~h}$ post inoculation when multiple cell necrosis has begun. Potato transcripts with putative functions related to biotic stress tolerance and defence against pathogens were upregulated, including a putative Nudix hydrolase that may play a role in defence against oxidative stress. $A$. solani transcripts encoding putative pathogenicity factors, such as cell wall degrading enzymes and metabolic processes that may be important for infection. We therefore identified the differential expression of several potato and $A$. solani transcripts that present a group of valuable candidates for further studies into their roles in immunity or disease development.

Keywords: early blight; RNAseq; necrotroph; Solanum tuberosum; plant-pathogen interaction

\section{Introduction}

Early blight of potato is a disease caused by fungi belonging to the genus of Alternaria. Even though several species of Alternaria, such as A. alternata and A. grandis have been indicated as the causal agent of potato early blight [1,2], $A$. solani is considered to be the main causal agent in Sweden [1]. A. solani is generally considered to be a necrotrophic fungus and the large-scale necrosis of infected tissues and subsequent defoliation, if left untreated, lead to the potential for early blight to halve potato yield [3]. The disease is currently controlled by fungicide treatment, however, fungicide resistance in A. solani populations has been reported for several of the commonly used fungicides [4]. Although cultivars with varying levels of early blight resistance exist, the resistance is suggested to be quantitative since no specific resistance $(R)$ genes have been identified, despite extensive investigation. Resistance appears to be closely linked to the maturity of cultivars and exhibits quantitative inheritance and race-specific resistance has so far not been observed [5]. 
The $A$. solani infection process was analyzed in a histopathological study of three different cultivars with varying early blight resistance by Dita et al. [6]. This study found that $A$. solani forms appressoria to penetrate host tissue and that the cultivar with the highest level of early blight resistance displayed hypersensitive response (HR) like symptoms, such as a granular structure of the cytoplasm and a thickened cell wall in the epidermal cells where the appressoria were formed. Due to the necrotrophic lifestyle of $A$. solani, the positive correlation of HR like symptoms and early blight resistance is puzzling, since necrotrophic pathogens are generally considered to benefit from HR in establishing infection $[7,8]$. In a recent study, we showed that, in contrast with the generally reported larger role of jasmonic acid (JA) in the defense against necrotrophic plant pathogens, potato requires intact salicylic acid (SA) signaling for defenses against $A$. solani [9]. We found that SA deficient plants displayed increased lesion development and less $\mathrm{H}_{2} \mathrm{O}_{2}$ production. One possible interpretation of these data is that $A$. solani is in fact not a true necrotroph but a hemibiotroph with a very short biotrophic phase.

In our recent work, we used microarrays to analyze the transcriptional changes occurring upon infection with $A$. solani in the susceptible potato cultivar Désirée, and SA and JA deficient lines where the earliest time point of sampling was $24 \mathrm{~h}$ post inoculation [9]. In the current study, we continued our investigation of $A$. solani induced transcriptional changes in potato in more detail. We have now used RNA sequencing to study the transcriptional changes occurring in potato foliage due to infection with $A$. solani in the same potato cultivar as used in our previous study. Additionally, the use of RNA sequencing allowed for the analysis of transcriptional changes in $A$. solani during the infection process. We focused on the transcriptional changes of A. solani and S. tuberosum in, and near, the inoculated area, starting as early as $1 \mathrm{~h}$ post inoculation up to $48 \mathrm{~h}$ post inoculation. Since, the A. solani-potato interaction displays some characteristics generally not seen in necrotrophic plant-pathogen interactions, such as the formation of appressoria and an important role of intact SA signaling in the restriction of lesion development, the early time points were specifically included to allow for detection of transcriptional changes in A. solani and inoculated potato before necrosis occurs. We therefore aimed to obtain data to understand if $A$. solani behaves as a hemi-biotroph with a short biotrophic phase on potato, or acts more like a necrotroph even from the early onset of infection.

\section{Results}

\subsection{Alternaria solani Infection Progress over a Time Course of 48 Hours}

In this study Alternaria solani conidia were used as inoculum. The A. solani conidia are claviform in shape (i.e., shaped like clubs or baseball bats) and can form multiple germ tubes (Figure 1). Germination of the conidia occurs under high humidity conditions, independent of the presence of a host. Conidia, both in vitro and in the inoculation droplet on a potato leaf, were observed to germinate within one hour (Figure 1). Six hours post inoculation (hpi) on the potato leaf, further growth of the germ tubes both towards and away from the plant epidermal cell surface occurred. At 12 hpi the germ tubes had formed a network of fungal growth within the inoculation droplet, and the first formation of appressoria and penetration had occurred. After $24 \mathrm{hpi}$, necrosis of the first epidermal cells on the adaxial side of the leaf due to A. solani infection was observed (Figure 2A), and the presence of appressoria was observed consistently (Figure 2B). Host cell death increased, and at $48 \mathrm{hpi}$ the necrosis of groups of multiple epidermal cells and mesophyll cells was observed (Figure 2C). Additionally, emergence of hyphae through the stomata on the abaxial side of the leaf was observed (Figure 2D). 

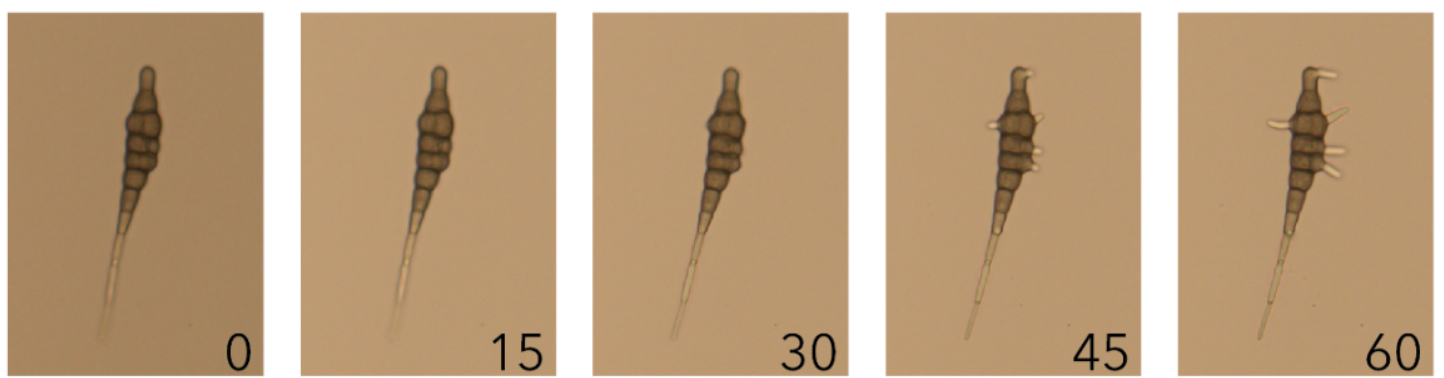

Figure 1. Germination of A. solani conidium. A. solani conidium in sterile tap watered imaged every 15 min for the first hour after harvesting. The numbers indicate minutes after harvest.

A
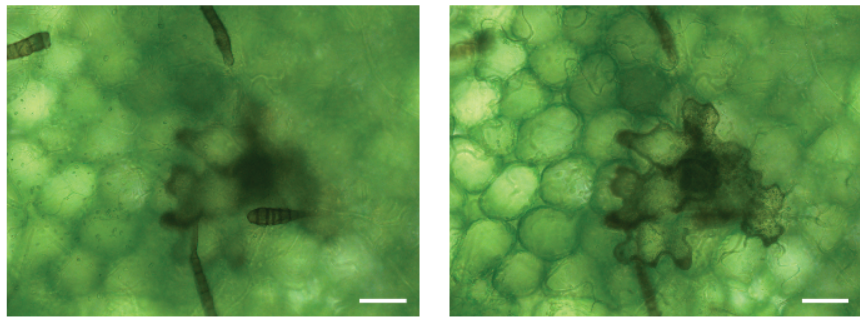

B
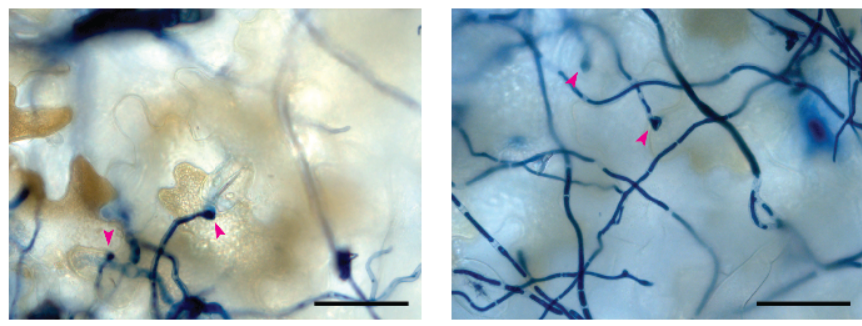

C
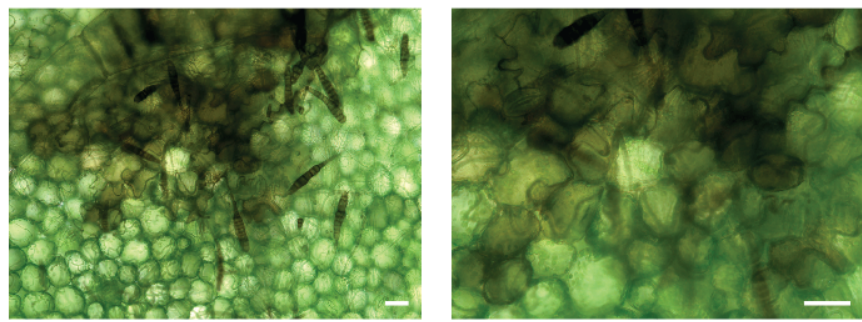

D

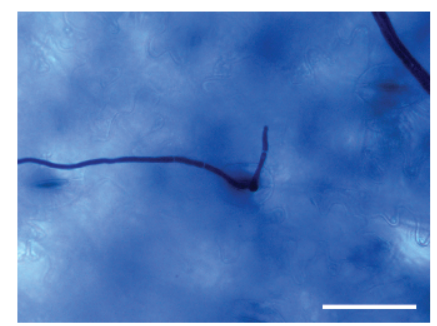

Figure 2. Infection of potato by A. solani. Representative micrographs of (A) death of a potato adaxial epidermal cell due to $A$. solani infection as observed in perfluorodecalin prepared samples harvested at 24 hpi. (B) Appressoria formed by A. solani to penetrate the adaxial side of the leaf at $24 \mathrm{hpi}$ as observed in trypan blue stained samples harvested at $24 \mathrm{hpi}$. Appressoria are indicated with a pink arrow. (C) Adaxial epidermal and mesophyll cell death due to A. solani as observed in perfluorodecalin prepared samples harvested 48 hpi. (D) Emergence of $A$. solani hyphae through a stoma on the abaxial side of the leaf as observed in trypan blue stained samples harvested at $48 \mathrm{hpi}$. Scale bars in all images correspond to $50 \mu \mathrm{m}$. 


\subsection{Mapping of Reads to Potato and A. solani Reference Genomes}

The response of potato gene expression to infection with $A$. solani and the changes occurring in $A$. solani gene expression during the infection of potato were analyzed using RNA sequencing. Drop inoculated samples were harvested at 1, 6, 12, 24, and 48 hours post inoculation (hpi). Three biological replicates were used for each sample. Mapping of the reads was performed first to the potato reference genome and subsequently to the A. solani reference genome. The total number of reads, the percentage of reads mapping to the $S$. tuberosum genome and the percentage of $S$. tuberosum unmapped reads mapping to the $A$. solani genome are presented in Table 1 . Due to the lack of transcript annotations for the $A$. solani genome, annotations were generated using the microbial fast annotation tool RASTtk and by NCBI BLAST analysis against $A$. alternata [10].

Table 1. Transcriptome statistics of $S$. tuberosum and A. solani during infection. Total reads (million), percentage of reads mapping to potato reference genome and percentage of reads unmapped to potato genome mapping to $A$. solani reference genome for all $A$. solani inoculated samples per time point, average of biological replicates given.

\begin{tabular}{cccccc}
\hline & \multicolumn{5}{c}{ Time Point (Hours Post Inoculation) } \\
\hline & $\mathbf{1}$ & $\mathbf{6}$ & $\mathbf{1 2}$ & $\mathbf{2 4}$ & $\mathbf{4 8}$ \\
\hline Total reads (Million) & 27.33 & 28.23 & 31.06 & 29.55 & 35.17 \\
Mapping to S. tuberosum reference genome (\%) & 87.2 & 88.5 & 86.6 & 86.6 & 0.27 \\
Unmapped to S. tuberosum mapping to $A$. & 1.64 & 4.17 & 1.63 & 0.05 \\
solani reference genome (\%) & & &
\end{tabular}

\subsection{Differential Expression of Plant Transcripts during Infection}

The differential plant transcript expression analyses were performed for the A. solani versus mock inoculated samples at the five time points. Transcripts were considered to be differentially expressed when the adjusted $p$-value was $<0.05$. No $\log 2$ fold change cut-off was used. The number of differentially expressed transcripts (DETs) from the host plant for all time points is presented in Figure 3, and the complete list can be found in the Supplementary File S1. The number of DETs increased with time post inoculation. However, more DETs were found at $24 \mathrm{hpi}$ compared to $48 \mathrm{hpi}$, which may reflect a lower level of overall gene expression due to necrotic and dying tissue at $48 \mathrm{hpi}$.

\subsection{Mostly Unique Plant DETs at Different Time Points}

The overlap between S. tuberosum DETs at the five time points was analyzed (Figure 3) and the comparison revealed that none of the DETs were common to all five of the time points. The largest overlap in DETs was found between the latest three time points. However, the majority of the plant DETs for each time point were unique, indicating distinct plant responses to the progression from pathogen inoculation to cell death (Figure 3).

\subsection{Gene Ontology Enrichment Analysis}

In order to gain a better understanding of the function of the differentially expressed plant transcripts, a gene ontology (GO) enrichment analysis of the genes belonging to the DETs of the host plant, Solanum tuberosum, was performed. For the DETs at $1 \mathrm{hpi}$, no significantly enriched GO terms were found. For the other time points, several enriched $\mathrm{GO}$ terms were found. The top ten biological process $\mathrm{GO}$ terms for these time points and the overlap between them are visualized in Figure 4. 


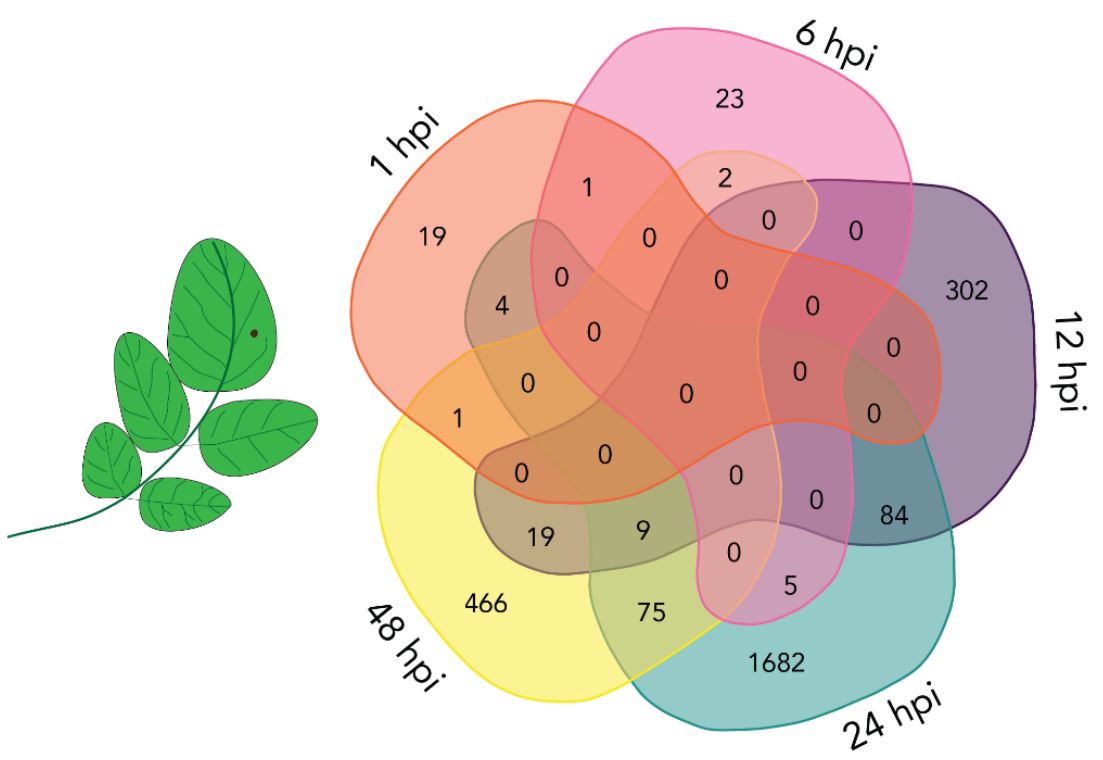

Figure 3. Venn diagram displaying overlap between differentially expressed transcripts (DETs) from potato detected at different time points after inoculation (hours post inoculation, hpi). Comparison between DETs at 1 hpi (orange), 6 hpi (pink), 12 hpi (purple), 24 hpi (green) and 48 hpi (yellow). Numbers represent unique or overlapping DETs between time points.

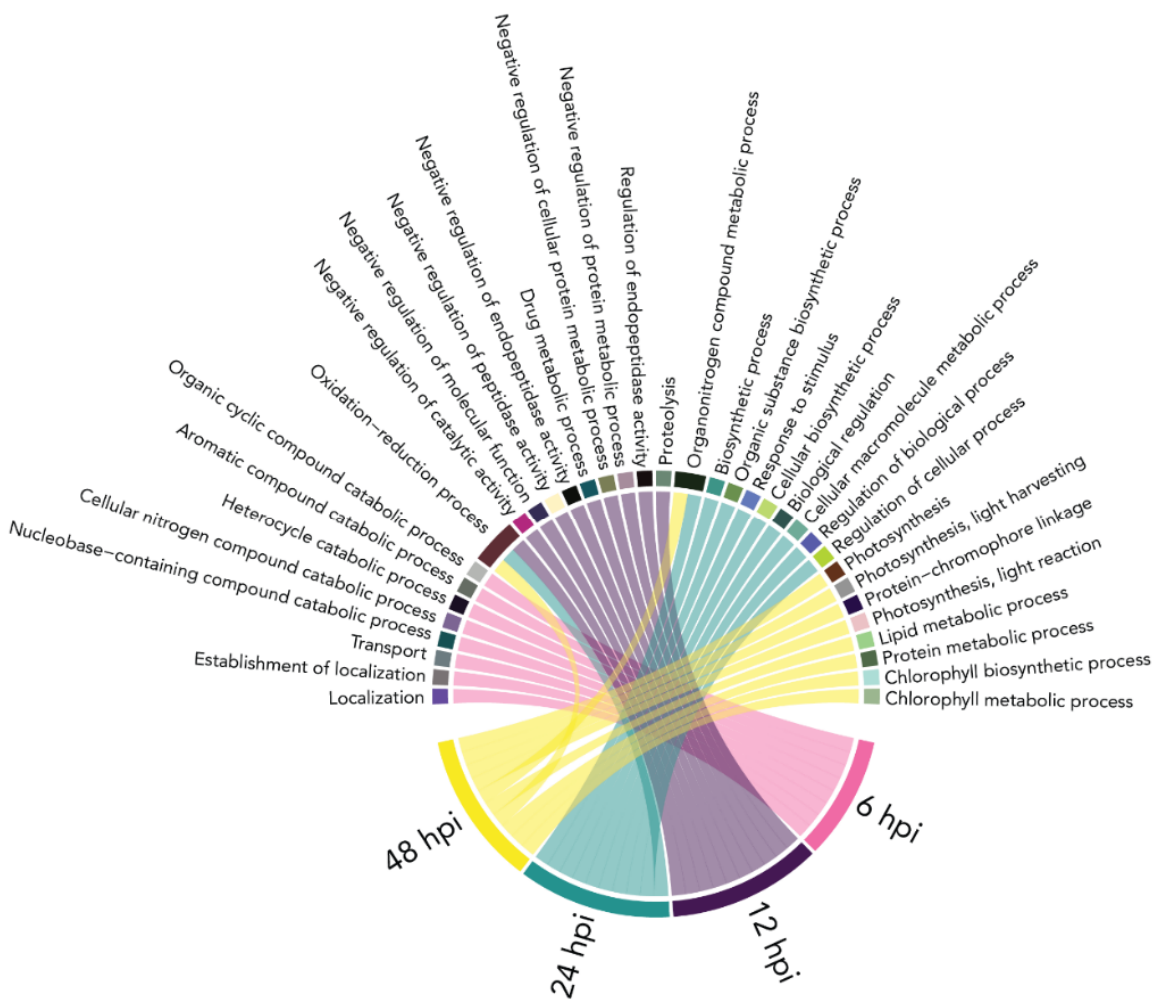

Figure 4. Gene ontology (GO) enrichment of differentially expressed plant transcripts at 6, 12, 24, and $48 \mathrm{~h}$ post A. solani inoculation (hpi). Chord diagram showing top 10 significantly enriched $($ FDR $<0.05)$ biological process GO-annotations for each time point.

\subsection{Differential Expression of Biotic Stress Related Plant Transcripts}

Further functional analysis of DETs at 12, 24 and 48 hpi was performed using MapMan software (version 3.6.0R1 https:/ / mapman.gabipd.org/home, last accessed on 20 November 2020) with the Solanum tuberosum PGSC transcript mapping file exported from 
gomapman.org [11]. Differential expression of transcripts related to 'biotic' stress were detected at $12 \mathrm{hpi}$ with upregulation of transcripts belonging to 'R genes' and 'signalling' bins. 'Cell wall' and 'proteolysis' transcripts showed both up- and downregulation. 'PR' proteins were mainly downregulated (Figure 5A). At $24 \mathrm{hpi}$, more transcripts related to biotic stress were differentially expressed, with 'R genes' 'signalling', 'cell wall', 'proteolysis', 'transcription factors', 'hormone signalling' and 'heat shock' transcripts showing differential expression (Figure 5B). At $48 \mathrm{hpi}$, in line with the general lower number of DETs compared to $24 \mathrm{hpi}$, the number of 'biotic stress' related transcripts was lower. At $24 \mathrm{hpi}$, downregulation of 'biotic stress' related 'transcription factor' transcripts was mainly observed, yet at $48 \mathrm{hpi}$, the transcripts in the 'transcription factor' bin showed mostly upregulation. Additionally, transcripts related to 'hormone signalling' showed more upregulation at 48 hpi compared to the earlier time points (Figure 5C).
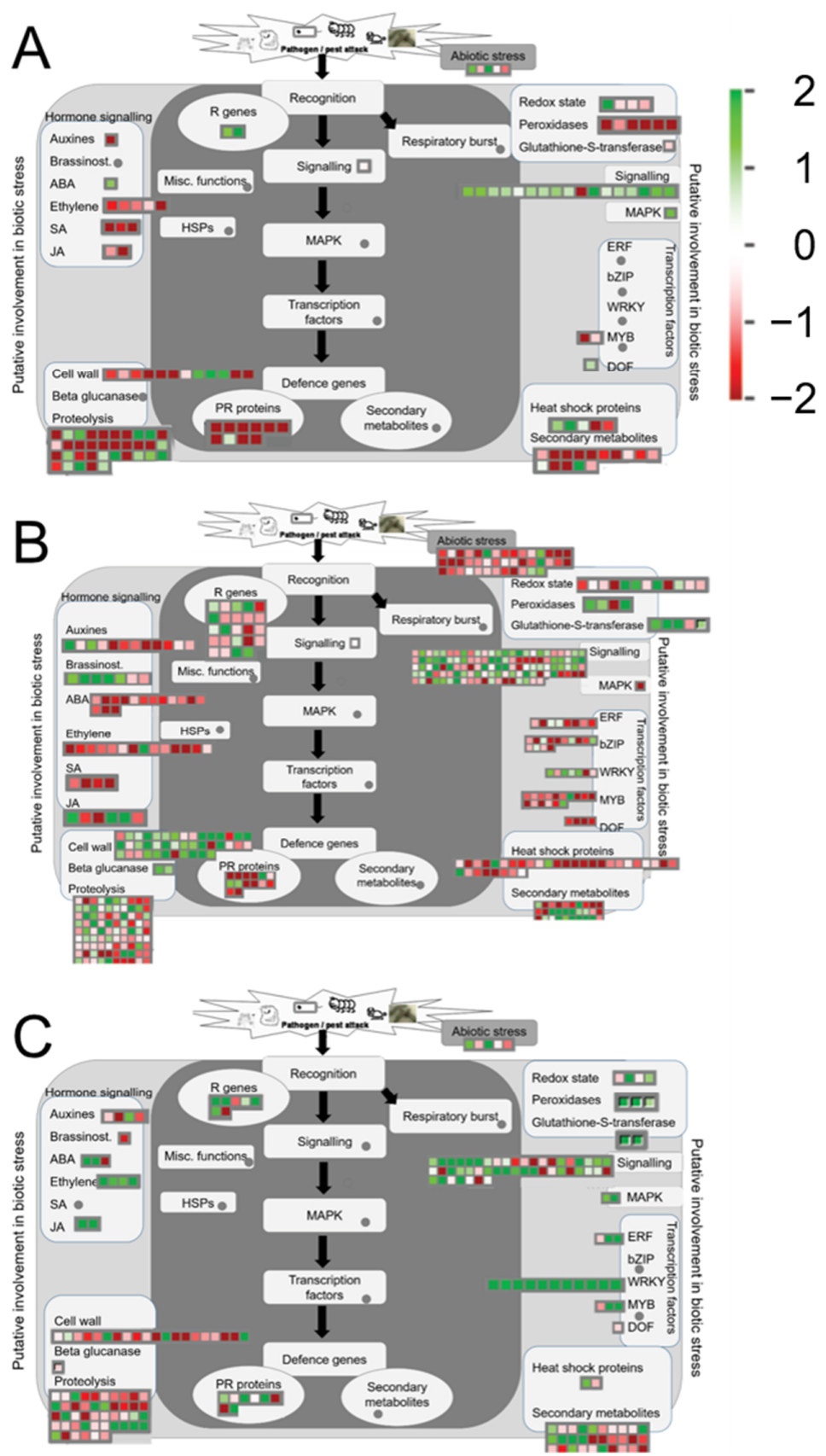

Figure 5. MapMan illustration of DETs belonging to the 'Biotic stress' BIN at (A) 12 hpi, (B) 24 hpi (C) 48 hpi. Log2 fold change is indicated as gradient from green (upregulated) to red (downregulated). 


\subsection{Differential Expression of A. solani Transcripts during Infection}

Differential A. solani transcript expression analyses were performed by comparing the A. solani inoculated samples at $6,12,24$, and $48 \mathrm{hpi}$ with the $1 \mathrm{hpi}$ sample. The number of A. solani DETs is presented in Table 2, and the complete list is given in the supplementary File S2. The number of DETs increased with time, with the exception of $48 \mathrm{hpi}$, when the fewest DETs were detected (Figure 6). The overlap between $A$. solani DETs at the four time points was analyzed (Figure 6). The A. solani DETs at the different time points show more overlap than the potato DETs. The largest overlap was observed between two consecutive time points. Notably, of the seven DETs observed for the last time point, the majority of the genes were also differentially expressed in all other time points (Figure 6).

Table 2. Top 10 differentially expressed potato transcripts in $A$. solani inoculated samples at $1 \mathrm{hpi}$. Transcript ID, log2 Fold change, and the gene descriptions are displayed.

\begin{tabular}{ccc}
\hline Transcript ID & log2 Fold Change & Gene Description \\
\hline PGSC0003DMT400020751 & 7.74 & Hydrolase \\
PGSC0003DMT400029007 & 7.65 & ATPase \\
PGSC0003DMT400021742 & 7.65 & Mutt domain protein \\
PGSC0003DMT400078504 & -7.56 & ALG2-interacting protein X \\
PGSC0003DMT400026165 & -7.57 & Stress regulated protein \\
PGSC0003DMT400076667 & -7.66 & WRKY transcription factor \\
PGSC0003DMT400006755 & -7.81 & Protein disulfide isomerase \\
PGSC0003DMT400061097 & -7.89 & Phosphomethylpyrimidine kinase \\
PGSC0003DMT400079490 & -8.45 & Chromatin remodeling complex \\
PGSC0003DMT400073533 & -8.57 & subunit \\
\hline
\end{tabular}
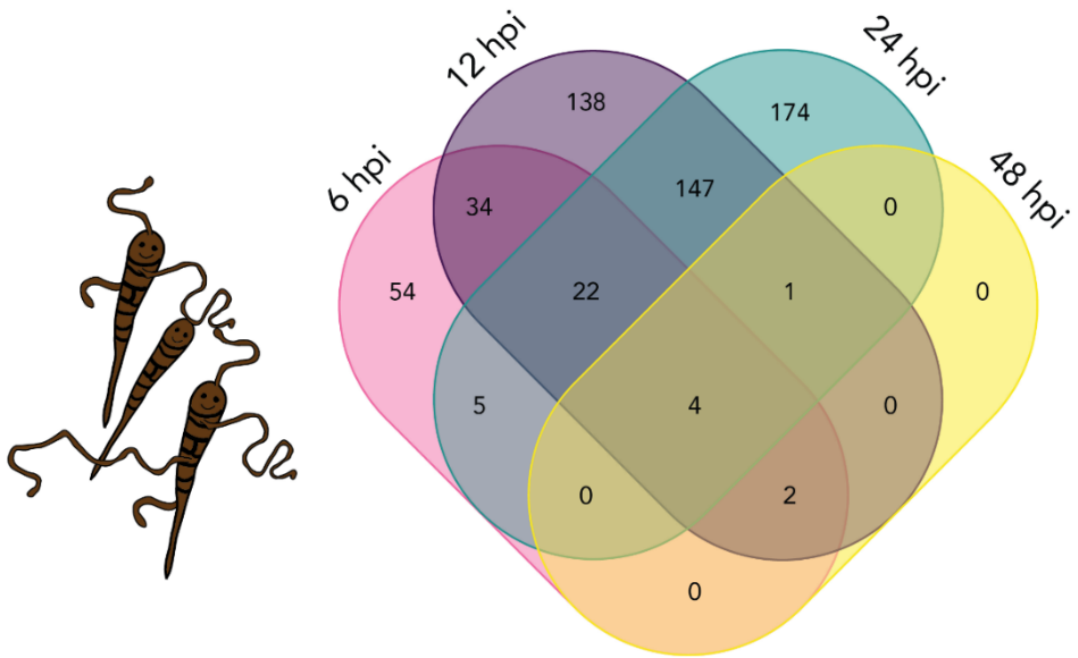

Figure 6. Venn diagram displaying overlap between the numbers of differentially expressed transcripts (DETs) from A. solani at different time points. Overlap between A. solani DETs at 6 hpi (pink), 12 hpi (purple), 24 hpi (green) and 48 hpi (yellow).

\subsection{Quantitative Real Time PCR Gene Expression Analysis Correlates Well with RNA Sequencing Data}

The differential expression of the selected top A. solani transcripts, found both across all of the different sampling time points (Table 3 ) and at specific time points only (Table 4), was confirmed by quantitative RT-PCR (qRT-PCR) performed on independent biological replicates. A Pearson correlation test showed a significant correlation between the RNA sequencing and qRT-PCR data sets with an R2 value of 0.9162 and a correlation coefficient of 0.9572 ( $p$ value $<0.0001$ ), validating the RNA sequencing data. A linear regression of the correlation is plotted in Supplementary Figure S1. 
Table 3. Differentially expressed A. solani transcripts overlapping in A. solani inoculated samples at 6, 12, 24 and 48 hpi. Transcript ID, $\log 2$ fold change, and the gene descriptions based on the RATtk v1.073 and BLAST analysis are displayed.

\begin{tabular}{|c|c|c|c|c|c|c|}
\hline \multirow[t]{2}{*}{ Transcript ID } & \multicolumn{3}{|c|}{ Log2 Fold Change } & \multicolumn{2}{|c|}{$\begin{array}{l}\text { Gene Description } \\
\text { RASTtk-v1.073 }\end{array}$} & \multirow[t]{2}{*}{$\begin{array}{l}\text { Gene Description } \\
\text { Alternaria alternata }\end{array}$} \\
\hline & 6 hpi & 12 hpi & 24 hpi & 48 hpi & & \\
\hline mRNA_3291 & -2.68 & -8.17 & -4.52 & -4.52 & Pectate lyase (EC 4.2.2.2) & pectate lyase precursor \\
\hline mRNA_8720 & -2.54 & -4.34 & -8.14 & -6.31 & $\begin{array}{l}\text { Inositol-1-phosphate } \\
\text { synthase (EC 5.5.1.4) }\end{array}$ & $\begin{array}{l}\text { Myo-inositol-1-phosphate } \\
\text { synthase }\end{array}$ \\
\hline mRNA_10760 & 4.86 & 6.02 & 5.78 & 6.74 & hypothetical protein & $\begin{array}{l}\text { NADP-dependent } \\
\text { mannitol dehydrogenase }\end{array}$ \\
\hline mRNA_10750 & 5.62 & 7.78 & 7.53 & 6.69 & $\begin{array}{c}\text { Lead, cadmium, zinc } \\
\text { and mercury transporting } \\
\text { ATPase } \\
\text { (EC 3.6.3.3) (EC 3.6.3.5) }\end{array}$ & potassium/sodium eff \\
\hline
\end{tabular}

Table 4. Top 5 up- and downregulated A. solani transcripts at 6, 12, 24 and 48 hpi compared to 1 hpi. Transcript ID, log2 Fold change, and the gene descriptions based on the RATtk v1.073 and BLAST analysis are displayed. Predicted signal peptide determined by SignalP 5.0 with likelihood $>0.9$, and predicted non-cytoplasmic domain based on InterPro analysis [12]. $x$ indicates presence.

\begin{tabular}{|c|c|c|c|c|c|}
\hline $\begin{array}{l}\text { Time } \\
\text { Point }\end{array}$ & Transcript ID & $\log ^{2}$ Fold Change & $\begin{array}{l}\text { Gene Description } \\
\text { RASTtk-v1.073 }\end{array}$ & $\begin{array}{l}\text { Gene Description } \\
\text { Alternaria alternata }\end{array}$ & $\begin{array}{l}\text { Predicted Signal } \\
\text { Peptide/Non- } \\
\text { Cytoplamic } \\
\text { Domain }\end{array}$ \\
\hline \multirow[t]{10}{*}{6 hpi } & mRNA_9018 & 7.98 & $\begin{array}{c}\text { Aldehyde } \\
\text { dehydrogenase (EC } \\
1.2 .1 .3)\end{array}$ & $\begin{array}{c}\text { aldehyde } \\
\text { dehydrogenase }\end{array}$ & \\
\hline & mRNA_10227 & 6.96 & $\begin{array}{c}\text { Acetyl-CoA } \\
\text { hydrolase/transferase } \\
\text { family protein }\end{array}$ & hypothetical protein & \\
\hline & mRNA_11966 & 6.60 & hypothetical protein & hypothetical protein & $x / x$ \\
\hline & mRNA_9568 & 6.57 & hypothetical protein & hypothetical protein & \\
\hline & mRNA_5212 & 6.51 & $\begin{array}{l}\text { Malate dehydrogenase } \\
\quad \text { (EC 1.1.1.37) }\end{array}$ & $\begin{array}{l}\text { malate } \\
\text { dehydrogenase-like } \\
\text { protein }\end{array}$ & \\
\hline & mRNA_9008 & -4.90 & hypothetical protein & $\begin{array}{c}\text { hypothetical protein } \\
\text { S-adenosyl-L- }\end{array}$ & $x / x$ \\
\hline & mRNA_914 & -5.75 & hypothetical protein & $\begin{array}{l}\text { methionine-dependent } \\
\text { methyltransferase }\end{array}$ & \\
\hline & mRNA_4527 & -5.99 & hypothetical protein & hypothetical protein & \\
\hline & mRNA_9891 & -6.42 & $\begin{array}{l}\text { monooxygenase } \\
\text { FAD-binding protein }\end{array}$ & monooxygenase & \\
\hline & mRNA_8569 & -6.92 & hypothetical protein & & $x / x$ \\
\hline \multirow[t]{10}{*}{12 hpi } & mRNA_9018 & 10.21 & $\begin{array}{c}\text { Aldehyde } \\
\text { dehydrogenase (EC } \\
1.2 .1 .3)\end{array}$ & $\begin{array}{c}\text { aldehyde } \\
\text { dehydrogenase }\end{array}$ & \\
\hline & mRNA_29 & 8.93 & Trehalase (EC 3.2.1.28) & trehalase & $x / x$ \\
\hline & mRNA_10328 & 8.82 & hypothetical protein & hypothetical protein & \\
\hline & mRNA_11100 & 8.70 & hypothetical protein & opsin-1 & \\
\hline & mRNA_5135 & 8.70 & hypothetical protein & GroES-like protein & \\
\hline & mRNA_4571 & -5.43 & hypothetical protein & hypothetical protein & $x / x$ \\
\hline & mRNA_10884 & -5.46 & hypothetical protein & hypothetical protein & \\
\hline & mRNA_8569 & -5.79 & hypothetical protein & & $x / x$ \\
\hline & mRNA_714 & -5.97 & $\begin{array}{c}\text { Glycerol-3-phosphate } \\
\text { dehydrogenase } \\
\text { [NAD }(\mathrm{P}) \% 2 \mathrm{~B}](\mathrm{EC} \\
1.1 .1 .94)\end{array}$ & $\begin{array}{l}\text { NAD-dependent } \\
\text { glycerol-3-phosphate } \\
\text { dehydrogenase }\end{array}$ & \\
\hline & mRNA_3291 & -8.17 & Pectate lyase (EC 4.2.2.2) & pectate lyase precursor & $x / x$ \\
\hline
\end{tabular}


Table 4. Cont.

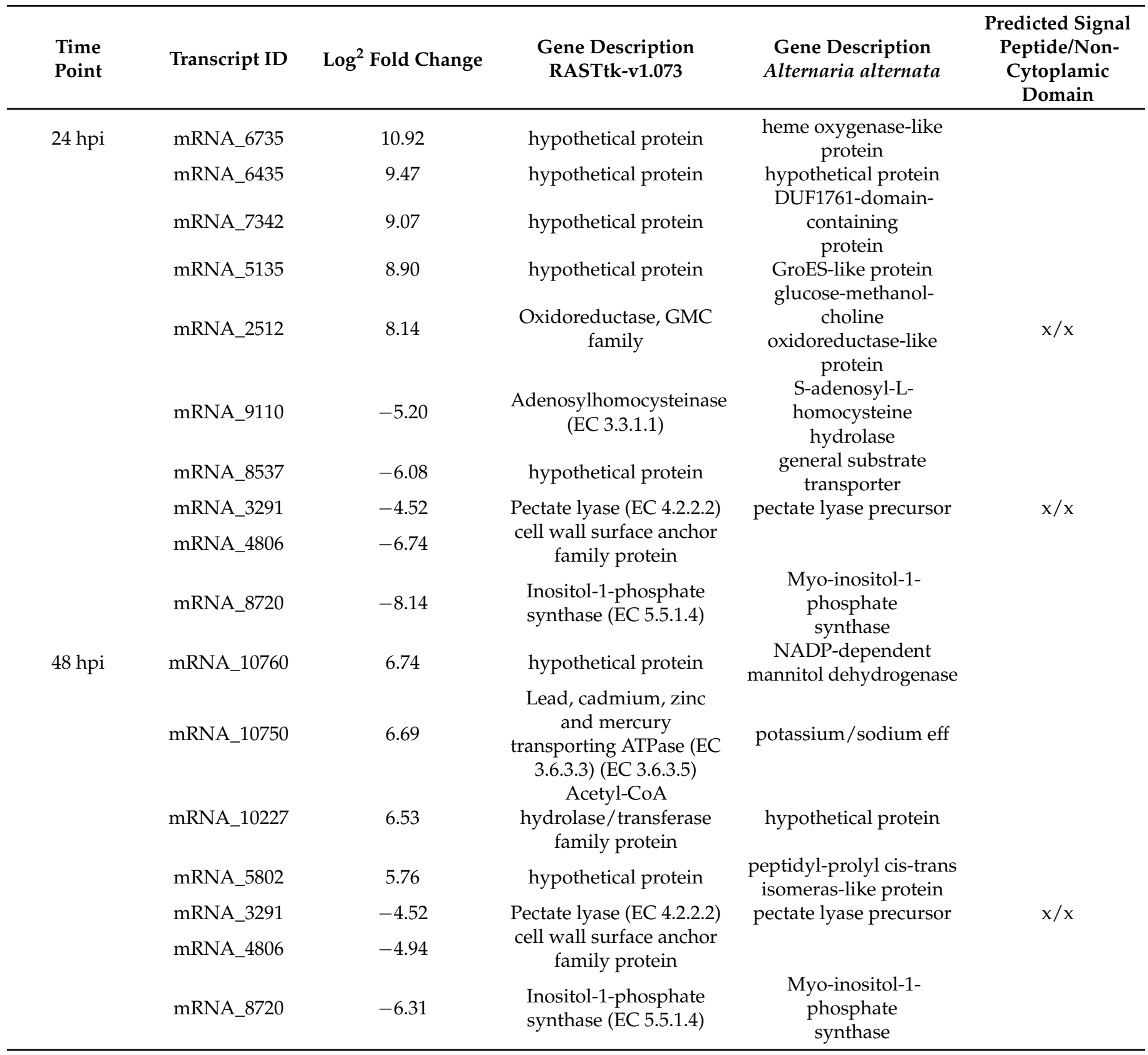

\section{Discussion}

\subsection{Differential Expression of Solanum tuberosum Transcripts}

At 1 and $6 \mathrm{~h}$ post inoculation, the $A$. solani conidia had started germination, but no formation of appressoria or penetration had occurred. However, for both time points, we detected DETs for S. tuberosum (supplementary File S1). At $1 \mathrm{hpi}$, downregulation of a gene annotated as stress regulated protein was observed (Table 2). This gene was shown to be upregulated by the synthetic SA homolog benzothiadiazole (BTH), but downregulated by the plant resistance inducer $\beta$-aminobutyric acid (BABA) (Results from AN Massa, KL Childs, H Lin, GJ Bryan, G Giuliano and CR Buell [13], visualized in Potato eFP browser by D Winter, B Vinegar, H Nahal, R Ammar, GV Wilson and NJ Provart [14]). One of the most highly upregulated transcripts at 1 hpi encoded a Mutt domain protein (Table 2). This transcript was also differentially expressed at $48 \mathrm{hpi}$, but at this time point showing downregulation ( $\log 2 \mathrm{FC}-7.76)$ (Supplementary File S1). The Mutt motif is also called 
the nucleoside diphosphates linked to some moiety X (Nudix) box. The closest Arabidopsis thaliana protein match to the potato Mutt domain protein was cytosolic Nudix hydrolase AtNUDX2, encoded by At5g47650. Overexpression of this gene in $A$. thaliana was shown to increase tolerance to oxidative stress [15]. Additionally, other cytosolic $A$. thaliana Nudix hydroxylases have been shown to play both positive and negative roles in biotic stress responses [16-18]. AtNUDX7 was shown to be a negative regulator of the EDS1 signaling pathway, a key component of plant immunity regulation. Knockout mutants of AtNUDX7 accumulated higher levels of SA than the control, showed constitutive expression of defense genes and had enhanced resistance against both the oomycete Hyaloperonospora arabidopsidis and the bacterium Pseudomonas syringae pv. maculicola [19]. AtNUDX8, however, was shown to positively regulate immunity with knockout mutants showing repressed SA signaling and enhanced susceptibility to $H$. arabidopsidis and P. syringae pv. maculicola [18] In summary, the Nudix proteins in A. thaliana play important roles in plant defenses and can influence the levels of SA. Further research into the potato Mutt domain protein and its role in susceptibility or resistance to $A$. solani is suggested. Among the plant DETs at $6 \mathrm{hpi}$ is a transcript encoding Sn-2 protein (PGSC0003DMT400006208) (supplementary File S1). The encoded protein shares $89 \%$ protein similarity with a putative PR-10 type pathogenesis-related protein in Nicotiana tabacum. Downregulation of this gene was also observed in pooled data from 24, 36 and $72 \mathrm{hpi}$ of potato infected with the late blight pathogen Phytophthora infestans (Results from AN Massa, KL Childs, H Lin, GJ Bryan, G Giuliano and CR Buell [13], visualized in Potato eFP browser by D Winter, B Vinegar, H Nahal, R Ammar, GV Wilson and NJ Provart [14]).

\subsection{Gene Ontology Enrichment of Drug Metabolic Processes at $12 \mathrm{hpi}$}

Gene ontology (GO) analysis of the plant differentially expressed transcripts was performed and at $12 \mathrm{hpi}$ the GO term 'drug metabolic process' was significantly enriched. One of the 'drug metabolic process' associated transcripts showing upregulation encodes pectinesterase 3. Pectinestarase, also called pectinmethylesterase, catalyzes the removal of methylesther groups from pectin [20]. The plant cell wall contains pectic polysaccharides and the degradation of the cell wall by necrotrophic plant pathogens, including pectin degradation, is required to release nutrients [21]. However, induction of plant pectinestarases during infection has also been observed. In Aradidopsis thaliana, a significant increase in gene expression of pectin methylesterase AtPME3 (At3g14310) was observed after inoculation with the necrotrophic fungus Botrytis cinerea and bacterium Pectobacterium carotovorum. AtPME3 was shown to be a susceptibility factor for infection by these pathogens, since pectin methylestarase mutant plants showed reduced susceptibility compared to the wild type [22]. The potato pectinestarase transcript we observed as differentially expressed upon inoculation with $A$. solani presents an interesting target for further study.

\subsection{Gene Ontology Enrichment of Photosynthesis Related Plant Transcripts at 48 hpi}

At $48 \mathrm{hpi}$, biological process GO terms associated to photosynthesis were significantly enriched (Figure 6). All transcripts belonging to the genes enriched in the photosynthesis GO terms were downregulated. More than half of these genes are annotated as a chlorophyll $\mathrm{a}-\mathrm{b}$ binding protein that is a part of the light harvesting complex of chlorophyll. Downregulation of genes involved in photosynthesis can either be an energy preserving strategy to invest in upregulation of defense genes, or a reaction to the large increase of $A$. solani-induced necrosis. Previously, a comparison of 22 different biotic stress interactions with eight different plant species revealed that the downregulation of photosynthesis genes was a global response to biotic stress [23].

\subsection{Differential Expression of Hormone Biosynthesis Related Transcripts during A. solani Infection}

Ethylene and jasmonic acid signaling are generally considered to be required for activation of defenses against necrotrophic plant pathogens [24]. However, interestingly, at $12 \mathrm{hpi}$ 
we observed downregulation of a transcript encoding 1-aminocyclopropane carboxylic acid oxidase 2 (PGSC0003DMT400036081) (supplementary File S1, an enzyme involved in the last step of ethylene biosynthesis [25]. At $24 \mathrm{hpi}$, this transcript was still downregulated, together with two other 1-aminocyclopropane carboxylic acid oxidase encoding transcripts (PGSC0003DMT400043087 and PGSC0003DMT40004444) (supplementary File S1). Similarly, transcripts for the JA biosynthesis involved enzyme lipoxygenase PGSC0003DMT4000 81909 at $12 \mathrm{hpi}$ and PGSC0003DMT400058933 at $24 \mathrm{hpi}$, and allene oxide synthase (PGSC000 3DMT400027377) were downregulated at 12 hpi and 24 hpi (supplementary File S1) However, other lipoxygenase transcripts (PGSC0003DMT400063468 and PGSC0003DMT400028158) showed upregulation at $24 \mathrm{hpi}$ and $48 \mathrm{hpi}$, respectively (supplementary File S1). Interestingly, at $12 \mathrm{hpi}$, three SA signaling transcripts all encoding salicylic acid carboxyl methyltransferases, were downregulated. The same transcripts were still downregulated at 24 hpi. Overexpression of a SA carboxyl methyltransferase gene from rice in $A$. thaliana rendered the plants more susceptible to infection by the hemibiotroph $P$. syringae and the obligate biotrophic fungus Golovinomyces orontii [26]. We previously showed that intact SA signaling is required for potato defenses against $A$. solani, since plants deficient in SA accumulation developed larger lesions [9]. This, together with the downregulation of ethylene and jasmonic acid biosynthesis genes observed at the early time points of $A$. solani, indicates that $A$. solani does not trigger responses characteristic for defense against necrotrophs in potato during the initial stages of infection.

\subsection{A. solani DETs Overlapping in all Four Time Points}

The RNA sequencing analysis revealed four A.solani DETs overlapping in all four time points, of which two transcripts were downregulated and two were upregulated in all time points compared to $1 \mathrm{hpi}$ (Table 3 ). One of the downregulated transcripts encodes a putative pectate lyase (Table 3). In the related fungus, Alternaria brassicicola, a pectate lyase encoding gene PL1332 was shown to be highly expressed up to $12 \mathrm{hpi}$ and was shown to be required for full virulence. Additionally, potato apoplast injection with a fusion protein of PL1332 resulted in necrosis of the plant tissue, indicating a cell wall degrading function [27]. In our analysis, we found the pectate lyase transcript was downregulated at $6,12,24$, and $48 \mathrm{hpi} \mathrm{compared} \mathrm{to} 1 \mathrm{hpi}$, indicating a possible role of the enzyme early on at the start of the germination phase in the presence of the plant. Additionally, the encoded protein is predicted to contain a signal peptide, and InterPro analysis predicts the protein to by non-cytoplasmic (Table 4). Another transcript upregulated in all time points encodes a NADP- dependent mannitol dehydrogenase (Table 3). NADP-dependent mannitol dehydrogenases catalyze the conversion of fructose into mannitol. Mannitol biosynthesis was shown to play a role in pathogenicity of A. alternata and A. brassicicola, but was not required for germination of conidia [28,29]. Moreover, pathogen mannitol has been shown to interfere with the formation of physical barriers in the plant host and to scavenge reactive oxygen species (ROS) [30].

\subsection{A. solani DETs Reveal Potential Pathogenicity Factors}

The most upregulated transcript (mRNA_9018) at both 6 and 12 hpi, encodes an aldehyde dehydrogenase (Table 4). This transcript was still found to be upregulated at 24 hpi $(\log 2 \mathrm{FC}=8.07)$ (supplementary File S2). Aldehyde dehydrogenases (ALDHs) are evolutionarily conserved enzymes employed for reactive molecule scavenging and are found in both plants and pathogens. ALDHs can also function as allergens, such as Alt a 10 from A. alternata (EC 1.2.1.3 ALDH) a causal agent of human allergies [31]. However, ALDHs were also shown to play a role in the pathogenicity of plant pathogens. RNA interference (RNAi) silencing of two ALDHs in the rice blast fungus Magnaporthe oryzae resulted in reduced conidiogenesis, vegetative growth and pathogenicity, the mutants were also highly sensitive to several oxidative and reductive stress inducing agents. These data indicate the importance of the ALDHs in tolerance of M. oryzae to reactive oxygen 
species (ROS) and reactive aldehydes generated by both the plant and pathogen during the infection process [32].

At 6 hpi compared to 1 hpi we observed downregulation of a transcript (mRNA_9891) predicted to encode a flavin-dependent monooxygenase (Table 4). This same transcript was also differentially expressed at $12 \mathrm{hpi}(\log 2 \mathrm{FC}=-5.36)$ (Supplementary File S2). Flavindependent monooxygenases catalyze a wide variety of oxygenation reactions and are found in many microorganisms. The gene $A b M a k 1$ encoding a flavin-dependent monooxygase in A. brassicicola was shown to be important for melanin production and conidial cell wall structure, since a lower melanin content and an aberrant cell wall were observed in $\Delta a b m a k 1$ mutants. The mutants were, however, not affected in pathogenicity and susceptibility to various stress conditions [33], indicating that this flavin-dependent monooxygenase in A. brassicicola is important for conidia structure. In A. solani, the conidia are highly melanized, yet the germ tubes are less melanized (Figure 1). If the encoded mRNA_9891 monooxygenase is important for melanization, downregulation during germination might be expected, which is what we observed. At $12 \mathrm{hpi}$, formation of the first appressoria was observed. The second highest upregulated transcript (mRNA_29) is predicted to encode a trehalase, catalyzing the conversion of trehalose to glucose. The transcript was still found to be upregulated at $24 \mathrm{hpi}(\log 2 \mathrm{FC}=7.04)$ (supplementary File S2). The encoded protein sequence is predicted to contain a signal peptide and non-cytoplasmic domain, and is thus likely secreted (Table 4). Trehalose is a disaccharide that has been shown to confer protection against various environmental stresses and is found in both plants and fungi [34]. In M. oryzae, both the synthesis of trehalose by a trehalose-6-phosphate synthase and the breakdown of trehalose by trehalase were shown to play a role in the infection of rice. The synthase was shown to be required for appressorium-mediated penetration and the trehalase for the development of infection after penetration. In summary, trehalose metabolism appears to play an important role in the pathogenicity of $M$. oryzae and our data suggests it may also be important for $A$. solani pathogenicity as well.

At 24 hpi, upregulation of mRNA_2512, annotated as encoding an oxidoreductase belonging to the glucose-methanol-choline (GMC) family, was seen (Table 4). This transcript also showed upregulation at $12 \mathrm{hpi}(\log 2 \mathrm{FC}=6.85)$ (supplementary File S2). The protein encoded by this transcript is predicted to contain a signal peptide and a non-cytoplasmic domain (Table 4). Characterized members of the GMC enzyme family from fungi have been shown to be relevant for lignocellulose degradation [35]. The encoded enzyme of mRNA_2512, therefore, might play a role in the degradation of the plant cell wall. At 24 hpi, compared to $1 \mathrm{hpi}$, downregulation of mRNA_9110 (predicted to be an S-adenosylL-homocysteine hydrolase (SAHH)) was observed (Table 4). This transcript was also downregulated at $12 \mathrm{hpi}(\log 2 \mathrm{FC}=-3.67)($ supplementary File S2). The enzyme SAHH is an important enzyme in the methylation potential in the cell. SAHH catalyzes the reversible hydrolysis of S-adenosylhomocysteine (SAH) to adenosine and homocysteine. SAH is converted into the major methyl donor S-adenosylmethionine (SAM). SAHH have been shown to be important in plant responses to pathogens in several plants [36]. However, SAHH has also been shown to have a role in fungal pathogenicity, e.g. in the chestnut blight fungus Cryphonectria parasitica. SAHH knockout mutants showed a reduced growth rate, absence of conidia and reduced virulence with reduced expression of virulence genes. We hypothesized that since SAHH is a key enzyme required for the methylation potential of the cell, the $\Delta$ sahh mutants have altered DNA methylation, which results in altered gene expression. However, the exact role of SAHH in C. parasitica virulence remains to be elucidated [37]. For the hypothetical protein transcripts mRNA_11966, mRNA_9008 and mRNA_8569, signal peptides and non-cytoplasmic domains were predicted, however further InterPro analysis did not predict any protein family membership. Their differential expression and indication of secretion make them interesting targets for validation studies of their role in pathogenicity as potential effector proteins. Fungal effector proteins are generally small ( $<200$ amino acids) cysteine-rich $(2-20 \%)$ secreted proteins [38]. The predicted protein sequence of mRNA_8569 is 109 amino acids long and has a cysteine 
content of 3.9\%. Functional validation of mRNA_8569 to determine whether the encoded protein operates as an effector would thus be of particular interest.

\section{Materials and Methods}

\subsection{Plant Material and Growth Conditions}

In Vitro maintained Solanum tuberosum cultivar Désirée was grown in 2 L pots containing commercial soil (Exclusiv Blom \& Plantjord, Emmaljunga Torvmull AB, Sweden) supplemented with $15 \mathrm{~mL}$ of fertilizer beads (Osmocote exact 3-4 months, ICL, Ipswich, UK). The plants were placed in an artificial light chamber with $14 \mathrm{~h}$ of $160 \mu \mathrm{mol} / \mathrm{s} / \mathrm{m}^{2}$, $65 \%$ relative humidity $(\mathrm{RH})$ at $20^{\circ} \mathrm{C}$. To allow acclimatization, the plantlets were covered with plastic cups during the first week in soil.

\subsection{Alternaria solani Maintenance and Inoculum Preparation}

Alternaria solani strain NL03003 (CBS 143772) [39] was maintained on V8 solid medium. The plates were kept in the dark at room temperature for 4 days, and subsequently placed in an $18{ }^{\circ} \mathrm{C}$ incubator equipped with UV-c light bulbs (model OSRAM HNS15G13 with dominant wavelength $254 \mathrm{~nm}$ ) supplying $8 \mathrm{~h}$ of UV-c light per day for 10 days to induce sporulation. Conidia for inoculations were harvested by flooding the plates with $10 \mathrm{~mL}$ sterile tap water and gently rubbing the mycelium to dislodge the conidia using plastic L-shaped spatulas and slow pipetting up and down. The concentration of conidia was determined using a Fuchs Rosenthal haemocytometer. For all infections, an inoculum of 25,000 conidia/mL was prepared.

\subsection{Microscopy}

Potato leaf punches inoculated with A. solani NL3030 were placed onto microscopy slides either in perfluorodecalin infiltrative imaging medium for improved visualization [40] or stained with trypan blue according to the method previously described [41]. Bright field microscopy of leaf punches and A. solani conidia in sterile tap water was performed using an inverted Zeiss Axio Observer D1. Micrographs were processed in ZEN 3.1 (blue edition) (Zeiss, Germany).

\subsection{Plant Inoculation with Alternaria solani}

Six-week old potato plants were arranged on trolleys containing 6 plants each. The trolleys were covered in plastic foil to reach $>95 \% \mathrm{RH}$ and placed inside an artificial light plant chamber at $20{ }^{\circ} \mathrm{C}$ and $90 \% \mathrm{RH}$, receiving $14 \mathrm{~h}$ of $160 \mu \mathrm{mol} / \mathrm{s} / \mathrm{m}^{2}$ light. Per treatment, 3 trolleys were prepared, from which one plant per trolley was sampled for each time point. 6 leaflets per plant were inoculated on the adaxial side of the leaf with either $10 \mu \mathrm{L}$ droplets containing 25,000 conidia/mL A. solani NL03003, or mock inoculum. The plants were inoculated right before the lights turned off, and the trolleys were covered with plastic foil for the first $24 \mathrm{~h}$ to ensure the high humidity required for the start of infection. Leaf disc samples were taken including the inoculation spot using an $8 \mathrm{~mm}$ cork borer, collecting 5 leaf discs from the same plant in one $1.5 \mathrm{~mL}$ microcentrifuge tube snap-frozen in liquid nitrogen. Samples were collected at $1,6,12,24$, and $48 \mathrm{~h}$ post inoculation (hpi), immediately snap-frozen, and ground in liquid nitrogen prior to RNA extraction.

\subsection{RNA Preparation and Sequencing}

RNA preparation and sequencing was performed as described previously [42]. Briefly, approximately $100 \mathrm{mg}$ of plant material (5 leaf discs) was used for RNA extraction using the Qiagen RNeasy Plant Mini kit (Qiagen, Hilden, Germany), according to the manufacturer's protocol, with an added DNase treatment interruption step. The DNase treatment was performed on column using the Invitrogen PureLink ${ }^{\mathrm{TM}}$ DNase set (Thermo Fisher Scientific, Massachusetts, USA) according to the manufacturer's protocol. The RNA quality and concentration were both corroborated by ND-1000 NanoDrop and by a 2100 Bioanalyzer using RNA Nano chips (Agilent Technologies, CA, USA). Polyadenylated messenger RNA was 
captured from $200 \mathrm{ng}$ total RNA per sample using magnetic beads and Illumina adaptors with sample-specific barcode sequences that were ligated before subsequent library amplification using PCR via the Illumina TruSeq RNA poly-A selection kit. Sequencing of $150 \mathrm{bp}$ paired-end libraries was carried out using the Illumina NovaSeq6000 S4 platform (SciLifeLab, Stockholm, Sweden). All raw sequencing data in this study have been deposited in National Center for Biotechnology Information (NCBI) under BioProject accession number PRJNA755645.

\subsection{Expression Analysis from RNA Sequencing}

Initial quality control $(\mathrm{QC})$ of the paired-end mRNA reads generated using Illumina high-throughput sequencing was performed at the NGI facility, Stockholm. An initial filtering step was performed for removal of ribosomal RNAs (rRNAs) by aligning reads with the silva and rfam databases using the Sortmerna-v2.1b [43] tool, and all TruSeq3 adapters were trimmed with Trimmomatic-v0.36 [44], setting MINLEN:20 in bases and SLIDINGWINDOW:5:20 with other parameters being the defaults. A second round QC check was performed on independent samples with FastQC v0.11.7 [45] and the multiple sample visualization MultiQC v1.6 [46] tool was used. The whole genome of PGSC_v4.03 (The Potato Genome Sequencing Consortium et al., 2011) was used for reference alignment. The mRNA reads were aligned to the genome using splice aligner STAR-v2.5.4a [47] tool with, -twopassMode Basic, -sjdbGTFfeatureExon CDS, -outReadsUnmapped Fastx, keeping other parameters as default. Transcript abundance was estimated with Salmon v1.3.0 [48]. Raw read counts were used for differential expression (DE) analysis with DESeq2 [49,50] and the built-in cross sample relative log expression" (RLE) [51] normalization was performed. The unmapped reads from the potato genome map were further processed and mapped to the Alternaria solani genome BMP0185 [52] using the same standardized methods for mapping, quantification and DE described above. The annotation to the $A$. solani genome was adopted and performed with fast annotation search tool RAStk [10]. In addition, BLAST searches (ncbi-blast-v2.9.0) with -max_target_seqs 1, -evalue 1e-5 were performed against transcripts of the closely related species Alternaria alternata for comparative analysis. Plant DE analysis was performed comparing the $A$. solani inoculated samples with the mock inoculated samples at the same time point. A. solani DE analysis was performed comparing all later time points individually with the first time point, $1 \mathrm{hpi}$. Transcripts were considered to be differentially expressed when the adjusted $p$ value $<0.05$. No $\log 2$ fold change cut-off was used. Venn diagrams were created using an online tool (http:/ / bioinformatics.psb.ugent.be/webtools/Venn/, last accessed on 5 November 2020). The gene ontology (GO) enrichment analysis was performed using ShinyGO v0.61 to detect significantly enriched GO terms (FDR $<0.05)$ using the default settings, with Solanum tuberosum as the matched species [53]. The top-10 enriched biological process GO terms were visualized in a chord diagram created using the R package circlize [54]. Additional functional analysis was performed in MapMan (version 3.6.0R1 https:/ / mapman.gabipd.org/home, last accessed on 20 November 2020) using the Solanum tuberosum PGSC transcript mapping file exported from gomapman.org [11]. Prediction of signal peptides from $A$. solani transcripts was performed by translating the mRNA nucleotide sequence into amino acids using EMBOSS Transeq [55], followed by eukaryote signal peptide prediction using SignalP 5.0 [56]. Sequences with a likelihood of $>0.9$ were considered to contain a predicted signal peptide. InterPro [12] was used to predict the presence of a non-cytoplasmic domain. The cysteine content of predicted proteins was performed using Expasy ProtParam [57].

\subsection{Validation of RNA Sequencing}

The top differentially expressed potato genes identified in the RNA sequencing analysis all produced multiple transcripts that were difficult to distinguish with quantitative RT-PCR Therefore only A. solani genes were chosen for the analysis. We have selected both up- and downregulated transcripts that were found across all the different sampling points 
or at specific time points only. The leaf disc samples used for the validation experiment were different biological replicates of the ones used for the RNA sequencing analysis. The total RNA was extracted with RNeasy Plant Mini kit (Qiagen, Hilden, Germany) and treated with TURBO DNase (Invitrogen, Vilnius, Lithuania) according to the manufacturers' protocols. The first strand cDNA was synthesized by oligo (dT) priming using Invitrogen SuperScript III Synthesis SuperMix for qRT-PCR kit (Invitrogen, Carlsbad, CA, USA). Quantitative real time PCR (qRT-PCR) was performed using PowerUp SYBR Green (Applied Biosystems, Vilnius, Lithuania) as the fluorescent dye and primers presented in supplementary Table S1. The $\beta$ tubulin gene from A. solani was used as a constitutively expressed endogenous control [58]. The results of the qRT-PCR assays were analyzed using the modified Delta-Delta Ct method as described in AO Avrova, E Venter, PRJ Birch and SC Whisson [59]. The obtained relative expression values were $\log 2$ transformed and their correlation to the $\log 2$ fold change values from RNA sequencing experiment was analyzed by Pearson correlation coefficient using GraphPad Prism version 9.2.0 for Windows (GraphPad Software, San Diego, CA, USA).

\section{Conclusions}

Early blight caused by Alternaria solani poses an increasing problem in potato production. However, we lack an understanding of defense and resistance mechanisms in potatoes. Here, we have presented an RNA sequencing-based transcriptome data set and analysis of potato cultivar Désirée infected with A. solani of time points before penetration, at the start of penetration and when necrosis of groups of plant cells occur. The majority of the differentially expressed plant transcripts identified were time point, and thus likely infection stage-specific, presenting an interesting data set for further mining of the potential resistance and susceptibility factors that might give clues for future improvement of host plant resistance to early blight in potato. Additionally, the differentially expressed A. solani transcripts detected in this study present interesting candidates for further validation studies on their role in pathogenicity.

Supplementary Materials: The following are available online at https:/ /www.mdpi.com/article/10 .3390 / plants10102212/s1, supplementary File S1: Output from differential plant transcript expression analysis at 1, 6, 12, 24, and $48 \mathrm{~h}$ between $A$. solani inoculated and mock inoculated samples. supplementary File S2: Output from differential A. solani transcript expression analysis of $A$. solani inoculated samples at 6, 12, 24, and $48 \mathrm{~h}$ compared to $1 \mathrm{hpi}$, supplementary Figure S1: Correlation between RNA sequencing and qRT-PCR gene expression data, supplementary Table S1: Primer pair sequences used for qRT-PCR validation of RNA sequencing.

Author Contributions: Conceptualization, S.M.B., E.L. and L.J.G.-B.; methodology, S.M.B. and L.J.G.B.; formal analysis, S.M.B., M.B.-S., D.L., G.V.S.; investigation, S.M.B., M.B.-S.; resources, L.J.G.-B.; data curation, S.M.B., L.J.G.-B., G.V.S.; writing—original draft preparation, S.M.B.; writing—review and editing, S.M.B., M.B.-S., L.J.G.-B., E.L., G.V.S., D.L.; visualization, S.M.B., M.B.-S.; supervision, E.L., L.J.G.-B.; project administration, L.J.G.-B.; funding acquisition, L.J.G.-B. All authors have read and agreed to the published version of the manuscript.

Funding: This work was funded by FORMAS grants 2015-00430 and 2019-00881 both granted to LGB. This project has also received funding from the European Union's Horizon 2020 research and innovation programme under Grant Agreement No 774340 (Organic Plus).

Institutional Review Board Statement: Not applicable.

Informed Consent Statement: Not applicable.

Data Availability Statement: All raw sequencing data in this study have been deposited in National Center for Biotechnology Information (NCBI) under BioProject accession number PRJNA755645. 
Acknowledgments: The authors acknowledge support from the National Genomics Infrastructure in Stockholm funded by Science for Life Laboratory, the Knut and Alice Wallenberg Foundation and the Swedish Research Council, the SLU Bioinformatics Infrastructure (SLUBI) for bioinformatics support, and the SNIC/Uppsala Multidisciplinary Center for Advanced Computational Science for assistance with massively parallel sequencing and access to the UPPMAX computational infrastructure.

Conflicts of Interest: The authors declare no conflict of interest.

\section{References}

1. Edin, E.; Andersson, B. The Early Blight Situation in Sweden-Species Abundance and Strobilurin Sensitivity. PPO Spec. Rep. 2014, 16, 83-84.

2. Landschoot, S.; Vandecasteele, M.; De Baets, B.; Höfte, M.; Audenaert, K.; Haesaert, G. Identification of A. Arborescens, A. Grandis, and A. Protenta as New Members of the European Alternaria Population on Potato. Fungal Biol. 2017, 121, 172-188. [CrossRef] [PubMed]

3. Leiminger, J.H.; Hausladen, H. Early Blight Control in Potato Using Disease-Orientated Threshold Values. Plant Dis. 2012, 96, 124-130. [CrossRef] [PubMed]

4. Odilbekov, F.; Edin, E.; Mostafanezhad, H.; Coolman, H.; Grenville-Briggs, L.J.; Liljeroth, E. Within-Season Changes in Alternaria Solani Populations in Potato in Response to Fungicide Application Strategies. Eur. J. Plant Pathol. 2019, 155, 953-965. [CrossRef]

5. Odilbekov, F.; Selga, C.; Ortiz, R.; Chawade, A.; Liljeroth, E. QTL Mapping for Resistance to Early Blight in a Tetraploid Potato Population. Agronomy 2020, 10, 728. [CrossRef]

6. Dita, M.A.; Brommonschenkel, S.H.; Matsuoka, K.; Mizubuti, E.S.G. Histopathological Study of the Alternaria solani Infection Process in Potato Cultivars with Different Levels of Early Blight Resistance. J. Phytopathol 2007, 155, 462-469. [CrossRef]

7. Govrin, E.M.; Levine, A. The Hypersensitive Response Facilitates Plant Infection by the Necrotrophic Pathogen Botrytis Cinerea. Curr. Biol. 2000, 10, 751-757. [CrossRef]

8. Balint-Kurti P: The Plant Hypersensitive Response: Concepts, Control and Consequences. Mol. Plant Pathol. 2019, 20, 1163-1178.

9. Brouwer, S.M.; Odilbekov, F.; Burra, D.D.; Lenman, M.; Hedley, P.E.; Grenville-Briggs, L.; Alexandersson, E.; Liljeroth, E.; Andreasson, E. Intact Salicylic Acid Signalling is Required for Potato Defence Against the Necrotrophic Fungus Alternaria Solani. Plant Mol. Biol. 2020, 104, 1-19. [CrossRef]

10. Brettin, T.; Davis, J.J.; Disz, T.; Edwards, R.A.; Gerdes, S.; Olsen, G.J.; Olson, R.; Overbeek, R.; Parrello, B.; Pusch, G.D.; et al. RASTtk: A Modular and Extensible Implementation of the RAST Algorithm for Building Custom Annotation Pipelines and Annotating Batches of Genomes. Sci. Rep. 2015, 5, 8365. [CrossRef]

11. Ramšak, Ž.; Baebler, Š.; Rotter, A.; Korbar, M.; Mozetič, I.; Usadel, B.; Gruden, K. Gomapman: Integration, Consolidation and Visualization of Plant Gene Annotations within the Mapman Ontology. Nucleic Acids Res. 2014, 42, D1167-D1175. [CrossRef] [PubMed]

12. Blum, M.; Chang, H.-Y.; Chuguransky, S.; Grego, T.; Kandasaamy, S.; Mitchell, A.; Nuka, G.; Paysan-Lafosse, T.; Qureshi, M.; Raj, S.; et al. The Interpro Protein Families and Domains Database: 20 Years On. Nucleic Acids Res. 2020, 49, D344-D354. [CrossRef] [PubMed]

13. Massa, A.N.; Childs, K.L.; Lin, H.; Bryan, G.J.; Giuliano, G.; Buell, C.R. The Transcriptome of the Reference Potato Genome Solanum Tuberosum Group Phureja Clone DM1-3 516R44. PLoS ONE 2011, 6, e26801. [CrossRef] [PubMed]

14. Winter, D.; Vinegar, B.; Nahal, H.; Ammar, R.; Wilson, G.V.; Provart, N.J. An “Electronic Fluorescent Pictograph" Browser for Exploring and Analyzing Large-Scale Biological Data Sets. PLoS ONE 2007, 2, e718. [CrossRef]

15. Ogawa, T.; Ishikawa, K.; Harada, K.; Fukusaki, E.; Yoshimura, K.; Shigeoka, S. Overexpression of an ADP-Ribose Pyrophosphatase, Atnudx2, Confers Enhanced Tolerance to Oxidative Stress in Arabidopsis Plants. Plant J. 2009, 57, 289-301. [CrossRef]

16. Ge, X.; Xia, Y. The Role of Atnudt7, a Nudix Hydrolase, in the Plant Defense Response. Plant Signal. Behav. 2008, 3, 119-120. [CrossRef]

17. Ishikawa, K.; Yoshimura, K.; Ogawa, T.; Shigeoka, S. Distinct Regulation of Arabidopsis ADP-Ribose/NADH Pyrophosphohydrolases, Atnudx6 And 7, In Biotic and Abiotic Stress Responses. Plant Signal. Behav. 2010, 5, 839-841. [CrossRef]

18. Fonseca, J.P.; Dong, X. Functional Characterization of a Nudix Hydrolase AtNUDX8 upon Pathogen Attack Indicates a Positive Role in Plant Immune Responses. PLoS ONE 2014, 9, e114119.

19. Dong, S.; Wang, Y. Nudix Effectors: A Common Weapon in the Arsenal of Plant Pathogens. PLoS Pathog. 2016, 12, e1005704. [CrossRef]

20. Sajjaanantakul, T.; Pitifer, L.A. Chapter 8-Pectinesterase. In The Chemistry and Technology of Pectin; Walter, R.H., Ed.; Academic Press: San Diego, CA, USA, 1991; pp. 135-164.

21. Houston, K.; Tucker, M.R.; Chowdhury, J.; Shirley, N.; Little, A. The Plant Cell Wall: A Complex and Dynamic Structure As Revealed by the Responses of Genes under Stress Conditions. Front. Plant Sci. 2016, 7, 984. [CrossRef]

22. Raiola, A.; Lionetti, V.; Elmaghraby, I.; Immerzeel, P.; Mellerowicz, E.J.; Salvi, G.; Cervone, F.; Bellincampi, D. Pectin Methylesterase is Induced in Arabidopsis Upon Infection and is Necessary for a Successful Colonization by Necrotrophic Pathogens. Mol. Plant-Microbe Interact. MPMI 2011, 24, 432-440. [CrossRef]

23. Bilgin, D.D.; Zavala, J.A.; Zhu, J.; Clough, S.J.; Ort, D.R.; DeLucia, E.H. Biotic Stress Globally Downregulates Photosynthesis Genes. Plant Cell Environ. 2010, 33, 1597-1613. [CrossRef] [PubMed] 
24. Li, N.; Han, X.; Feng, D.; Yuan, D.; Huang, L.-J. Signaling Crosstalk between Salicylic Acid and Ethylene/Jasmonate in Plant Defense: Do We Understand What They Are Whispering? Int. J. Mol. Sci. 2019, 20, 671. [CrossRef]

25. Kawai, Y.; Ono, E.; Mizutani, M. Evolution and Diversity of the 2-Oxoglutarate-Dependent Dioxygenase Superfamily in Plants. Plant J. 2014, 78, 328-343. [CrossRef]

26. Koo, Y.J.; Kim, M.A.; Kim, E.H.; Song, J.T.; Jung, C.; Moon, J.-K.; Kim, J.-H.; Seo, H.S.; Song, S.I.; Kim, J.-K.; et al. Overexpression of Salicylic Acid Carboxyl Methyltransferase Reduces Salicylic Acid-Mediated Pathogen Resistance in Arabidopsis Thaliana. Plant Mol. 2007, 64, 1-15. [CrossRef] [PubMed]

27. Cho, Y.; Jang, M.; Srivastava, A.; Jang, J.-H.; Soung, N.-K.; Ko, S.-K.; Kang, D.-O.; Ahn, J.S.; Kim, B.Y. A Pectate Lyase-Coding Gene Abundantly Expressed during Early Stages of Infection Is Required for Full Virulence in Alternaria brassicicola. PLoS ONE 2015, 10, e0127140. [CrossRef]

28. Vélëz, H.; Glassbrook, N.J.; Daub, M.E. Mannitol Biosynthesis is Required for Plant Pathogenicity by lternaria Alternata. Fems. Microbiol. Lett. 2008, 285, 122-129. [PubMed]

29. Calmes, B.; Guillemette, T.; Teyssier, L.; Siegler, B.; Pigné, S.; Landreau, A.; Iacomi, B.; Richomme, P.; Lemoine, R.; Simoneau, P. Role of Mannitol Metabolism in the Pathogenicity of the Necrotrophic Fungus Alternaria Brassicicola. Front. Plant Sci. 2013, 4, 131. [CrossRef]

30. Meena, M.; Upadhyay, R.S.; Prasad, V.; Zehra, A.; Gupta, V.K. Mannitol Metabolism during Pathogenic Fungal-Host Interactions under Stressed Conditions. Front. Microbiol. 2015, 6, 1019. [CrossRef]

31. Kustrzeba-Wójcicka, I.; Siwak, E.; Terlecki, G.; Wolańczyk-Mędrala, A.; Mędrala, W. Alternaria Alternata and its Allergens: A Comprehensive Review. Clin. Rev. Allerg Immunol. 2014, 47, 354-365. [CrossRef]

32. Abdul, W.; Aliyu, S.R.; Lin, L.; Sekete, M.; Chen, X.; Otieno, F.J.; Yang, T.; Lin, Y.; Norvienyeku, J.; Wang, Z. Family-Four Aldehyde Dehydrogenases Play an Indispensable Role in the Pathogenesis of Magnaporthe Oryzae. Front. Plant Sci. 2018, 9, 980. [CrossRef]

33. Pigné, S.; Zykwinska, A.; Janod, E.; Cuenot, S.; Kerkoud, M.; Raulo, R.; Bataillé-Simoneau, N.; Marchi, M.; Kwasiborski, A.; N'Guyen, G.; et al. A Flavoprotein Supports Cell Wall Properties in the Necrotrophic Fungus Alternaria Brassicicola. Fungal Biol. Biotechnol. 2017, 4, 1. [CrossRef]

34. Tournu, H.; Fiori, A.; Dijck, P.V. Relevance of Trehalose in Pathogenicity: Some General Rules, Yet Many Exceptions. PLoS Pathog. 2013, 9, e1003447. [CrossRef]

35. Sützl, L.; Foley, G.; Gillam, E.M.J.; Bodén, M.; Haltrich, D. The GMC Superfamily of Oxidoreductases Revisited: Analysis and Evolution of Fungal GMC Oxidoreductases. Biotechnol. Biofuels 2019, 12, 118. [CrossRef] [PubMed]

36. Li, X.; Huang, L.; Hong, Y.; Zhang, Y.; Liu, S.; Li, D.; Zhang, H.; Song, F. Co-Silencing of Tomato S-Adenosylhomocysteine Hydrolase Genes Confers Increased Immunity against Pseudomonas Syringae Pv. Tomato DC3000 and Enhanced Tolerance to Drought Stress. Front. Plant Sci. 2015, 6, 717. [CrossRef] [PubMed]

37. Liao, S.; Li, R.; Shi, L.; Wang, J.; Shang, J.; Zhu, P.; Chen, B. Functional Analysis of an S-Adenosylhomocysteine Hydrolase Homolog of Chestnut Blight Fungus. Fems. Microbiol. Lett. 2012, 336, 64-72. [CrossRef] [PubMed]

38. Lu, S.; Edwards, M.C. Genome-Wide Analysis of Small Secreted Cysteine-Rich Proteins Identifies Candidate Effector Proteins Potentially Involved in Fusarium graminearum-Wheat Interactions. Phytopathol 2016, 106, 166-176. [CrossRef] [PubMed]

39. Iftikhar, S.; Shahid, A.A.; Halim, S.A.; Wolters, P.J.; Vleeshouwers, V.G.A.A.; Khan, A.; Al-Harrasi, A.; Ahmad, S. Discovering Novel Alternaria Solani Succinate Dehydrogenase Inhibitors by in Silico Modeling and Virtual Screening Strategies to Combat Early Blight. Front. Chem. 2017, 5, 100. [CrossRef] [PubMed]

40. Littlejohn, G.R.; Mansfield, J.C.; Christmas, J.T.; Witterick, E.; Fricker, M.D.; Grant, M.R.; Smirnoff, N.; Everson, R.M.; Moger, J.; Love, J. An Update: Improvements in Imaging Perfluorocarbon-Mounted Plant Leaves with Implications for Studies of Plant Pathology, Physiology, Development and Cell Biology. Front. Plant Sci. 2014, 5, 140. [CrossRef]

41. Fernández-Bautista, N.; Domínguez-Núñez, J.A.; Moreno, M.M.C.; Berrocal-Lobo, M. Plant Tissue Trypan Blue Staining During Phytopathogen Infection. Bio-Protocol 2016, 6, e2078. [CrossRef]

42. Liang, D.; Andersen, C.B.; Vetukuri, R.R.; Dou, D.; Grenville-Briggs, L.J. Horizontal Gene Transfer and Tandem Duplication Shape the Unique CAZyme Complement of the Mycoparasitic Oomycetes Pythium oligandrum and Pythium periplocum. Front. Microbiol. 2020, 11, 2609. [CrossRef]

43. Kopylova, E.; Noé, L.; Touzet, H. SortMeRNA: Fast and Accurate Filtering of Ribosomal Rnas in Metatranscriptomic Data. Bioinformatics 2012, 28, 3211-3217. [CrossRef]

44. Bolger, A.M.; Lohse, M.; Usadel, B. Trimmomatic: A flexible trimmer for Illumina Sequence Data. Bioinformatics 2014, 30, 2114-2120. [CrossRef]

45. FastQC. Available online: https://www.bioinformatics.babraham.ac.uk/projects/fastqc/ (accessed on 15 October 2020).

46. Ewels, P.; Magnusson, M.; Lundin, S.; Käller, M. MultiQC: Summarize Analysis Results for Multiple Tools and Samples in a Single Report. Bioinformatics 2016, 32, 3047-3048. [CrossRef]

47. Dobin, A.; Gingeras, T.R. Mapping RNA-seq Reads with STAR. Curr. Protoc. Bioinform. 2015, 51, 11.14.11-11.14.19. [CrossRef]

48. Patro, R.; Duggal, G.; Love, M.I.; Irizarry, R.A.; Kingsford, C. Salmon Provides Fast and Bias-Aware Quantification of Transcript Expression. Nat. Methods 2017, 14, 417-419. [CrossRef]

49. Anders, S.; Huber, W. Differential Expression Analysis for Sequence Count Data. Genome Biol. 2010, 11, R106. [CrossRef] [PubMed] 
50. Anders, S.; McCarthy, D.J.; Chen, Y.; Okoniewski, M.; Smyth, G.K.; Huber, W.; Robinson, M.D. Count-Based Differential Expression Analysis of RNA Sequencing Data Using R and Bioconductor. Nat. Protoc. 2013, 8, 1765-1786. [CrossRef]

51. Love, M.I.; Huber, W.; Anders, S. Moderated Estimation of Fold Change and Dispersion for RNA-Seq Data with Deseq2. Genome Biol. 2014, 15, 550. [CrossRef] [PubMed]

52. Dang, H.X.; Pryor, B.; Peever, T.; Lawrence, C.B. The Alternaria Genomes Database: A Comprehensive Resource for a Fungal Genus Comprised of Saprophytes, Plant Pathogens, and Allergenic Species. BMC Genom. 2015, 16, 239. [CrossRef] [PubMed]

53. Ge, S.X.; Jung, D.; Yao, R. ShinyGO: A Graphical Gene-Set Enrichment Tool for Animals and Plants. Bioinformatics 2020, 36, 2628-2629. [CrossRef]

54. Gu, Z.; Gu, L.; Eils, R.; Schlesner, M.; Brors, B. Circlize Implements and Enhances Circular Visualization in R. Bioinformatics 2014, 30, 2811-2812. [CrossRef]

55. Madeira, F.; Park, Y.M.; Lee, J.; Buso, N.; Gur, T.; Madhusoodanan, N.; Basutkar, P.; Tivey, A.R.N.; Potter, S.C.; Finn, R.D.; et al. The EMBL-EBI Search and Sequence Analysis Tools APIs in 2019. Nucleic Acids Res. 2019, 47, W636-W641. [CrossRef]

56. Almagro Armenteros, J.J.; Tsirigos, K.D.; Sønderby, C.K.; Petersen, T.N.; Winther, O.; Brunak, S.; von Heijne, G.; Nielsen, H. SignalP 5.0 Improves Signal Peptide Predictions Using Deep Neural Networks. Nat. Biotechnol. 2019, 37, 420-423. [CrossRef] [PubMed]

57. Walker, J.M. The Proteomics Protocols Handbook; Humana Press: Totowa, NJ, USA, 2005.

58. Kumar, S.; Singh, R.; Kashyap, P.L.; Srivastava, A.K. Rapid Detection and Quantification of Alternaria Solani in Tomato. Sci. Hortic. 2013, 151, 184-189. [CrossRef]

59. Avrova, A.O.; Venter, E.; Birch, P.R.J.; Whisson, S.C. Profiling and Quantifying Differential Gene Transcription in Phytophthora Infestans Prior to and During the Early Stages of Potato Infection. Fungal Genet. Biol. 2003, 40, 4-14. [CrossRef] 